\title{
Dual Interleaved LLC Converter for High Power Applications and Wide Load Range
}

\author{
Michal Frivaldsky ${ }^{1}$, Jan Morgos ${ }^{1}$, Andrej Kanovsky ${ }^{2}$ \\ ${ }^{l}$ Department of Mechatronics and Electronics, University of Zilina, \\ Zilina, Slovakia \\ ${ }^{2}$ Delta Electronics Slovakia, \\ Nova Dubnica, Slovakia \\ michal.frivaldsky@fel.uniza.sk
}

\begin{abstract}
Dual interleaved LLC resonant converter with half bridge topology of main circuit characterized by high switching frequency $(500 \mathrm{kHz})$, high power density $\left(60 \mathrm{~W} /\right.$ inch $\left.^{3}\right)$ and high efficiency (above $96 \%$ ) over entire operational range $(20 \%-100 \%)$ is described. Focus was given on the practical design of power converter, which will be able to fulfil requirements on wide load range operation characterized by upcoming normative. Since proposed topology is based on dual interleaved LLC converter, the resonant component's critical tolerance was also investigated to secure reliable and optimal operational point. Consequently, proposals for elimination of intolerance negative impact are also described. The results of theoretical analysis were verified directly through experimental measurements. Experimental results are finally compared with upcoming industrial standard 80 Plus Titanium.
\end{abstract}

Index Terms-Power density; Interleaved; LLC converter; High frequency transformer; High efficiency.

\section{INTRODUCTION}

Energy efficiency and power density become main qualitative indexes of power electronic systems. Key factors for continual increase of both indicators have environmental, as well as economical character. Nowadays, in the field of industrial and consumer electronic the international standards and regulations are determined by international organizations like, U.S Energy Star, 80 Plus, Climate Savers, German Blue Angel, etc...

LLC resonant converters have been discovered already in the seventies of the twentieth century, but the mass of the deployment occurs only in recent years because of their unique properties, and high efficiency. Therefore, its features and operation, even for interleaved configurations are well described in many articles and technical literature.

Operation at high switching frequency, soft commutation of power switches, optimal selection of power switches, the selection of magnetic core are prerequisites for the successful design of the high-power density supply. Nowadays, requirements on low stand-by consumption and high efficiency operation even at light loads are also required. Thus, design of proper configuration of main circuit is a big challenge almost, when compact size is

Manuscript received 3 October, 2018; accepted 24 April, 2019

This research was funded by a grant (No. APVV-15-0396) from the Slovak National grant Agency APVV. preferred [1]-[4].

This article describes practical design of switched mode power supply, which shall be suited for front-end power conversion. Initially main properties of the converter are identified, while the selection of proper topology is the main outcome of the procedure. The dual interleaved half-bridge LLC resonant converter exhibits better performance compared to standard full-bridge solution. Other improvements compared to existing solutions are related to practical application of the digital control, very high switching frequency and achievement of high-efficient operation (96\%). Thus, in this way the requirement on the increase of the power density are being met. Paper provides practical design of individual converter parts, and its experimental verification within various operational conditions.

\section{CONCEPT OF THE HIGH EFFICIENCY, WIDE-LOAD OPERATED, HIGH POWER DENSITY POWER SUPPLY}

To achieve high power density it is most perspective to utilize the Frond-End topology of power supply with an autonomous (offline) operation.

The Frond-End arrangement of the power supply includes two basic stages, the first one is the PFC stage which is responsible for power factor correction in each mode of operation, and another important task of the PFC stage is to generate constant DC voltage for energizing of the second stage the DC/DC converter. The DC/DC converter is designed to electrically isolate the primary side of the power supply from the secondary sides, effectively transform the energy to output and ensure the required outputs static and dynamic characteristics of the power supply.

Since this paper is focused to the design of DC/DC converter the PFC stage will not be further mentioned in the article. The process of design of the high-power density power supply can be divided into several steps. This proposal is graphically illustrated in Fig. 1. One of the basic prerequisites for the successful design of the power supply with high power density is a high switching frequency operation. The high switching frequency is beneficial to reduce the size of circuit elements including huge magnetic components. On the other hand, with the increase of switching frequency the switching losses of the power semiconductors increase. This limitation does not manage to 
overcome the presence of soft commutation at zero voltage switching (ZVS) and zero current switching (ZCS). Soft switching is particularly well feasible using resonant phenomena in quasi-resonant or resonant types of converters. Unfortunately, not all quasi-resonant or resonant types of converters are suitable for use in applications where the demands on wide range of input voltage and output load are made. The most preferable resonant topology for this field is LLC converter [5]-[8]. An application area of the LLC half-bridge DC/DC converter is in the power range from tens of watts up to one kilowatt [9], [10]. Full bridge topology is preferable, when output power in the range of 10 $\mathrm{kW}$ is required.

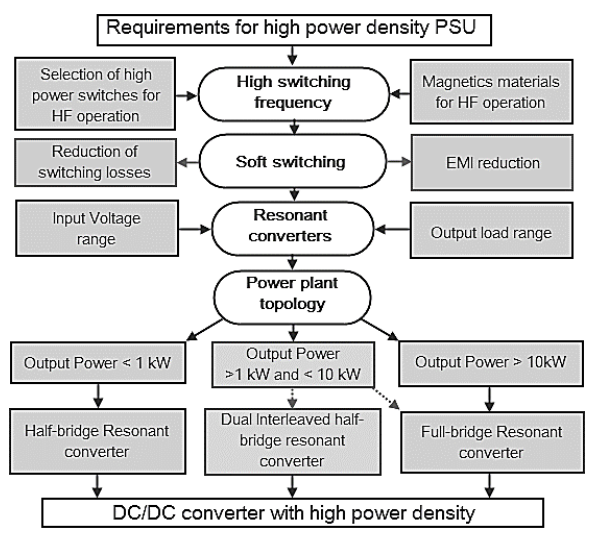

Fig. 1. Simplified design procedure of high-power density DC/DC converter.

At this point the questions arise:

- What is the appropriate topology for power supplies with high power density and with output power over $1 \mathrm{~kW}$ ?

- Is it possible to use half-bridge topology?

- Or is it better to take advantage of the full bridge?

Answers to these questions are not clear and are subjected to the requirements of the target application. Advantages of the parallel operation of the LLC converters are highly appreciated in the applications where high efficiency is required for wide range of the output load. Telecommunications are the typical example due to variation of the load depends on the day/night traffic. Based on the performed investigation it seems that for applications with output power of $1 \mathrm{~kW}$ and low output voltage is more convenient to use the involvement of two parallel-operated LLC converters (Fig. 2). The main reason is great advantage of this solution in the possibility of parallel operation of two DC/DC converters during heavy load and disconnection of one of the converter during light load.

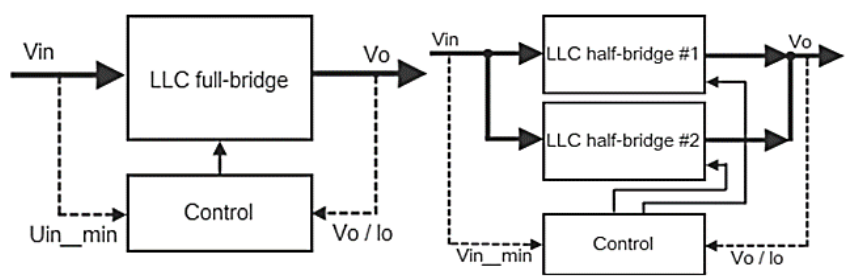

Fig. 2. Block schematic of full-bridge LLC converter (left) and dual halfbridge LLC converter (fight).

This unique feature involving two parallel - operated LLC converters has a favourable effect on achieving the higher efficiencies at low load (disconnecting one of the converters). Also due to the current cancellation effect (interleaved mode with 90 degrees of phase shift) a significant drop of output current ripple during heavy load can be achieved. Mentioned reduction is also beneficial for increase of the lifetime of the output capacitors.

In next chapters, more detailed description about the highefficiency/high power density-oriented design of dual interleaved, parallel - operated LLC converter will be given. We have focused on proper design of the most critical circuit components. Target input-output parameters of proposed converter are:

- Input voltage range $340 \mathrm{~V} \mathrm{dc}-400 \mathrm{~V} \mathrm{dc}$;

- Maximal output power $2.4 \mathrm{~kW}$;

- Nominal output voltage $48 \mathrm{~V} \mathrm{dc}$;

- Switching frequency $500 \mathrm{kHz}$.

\section{High FREQUENCY TRANSFORMER DESIGN - CONSTRAINS}

More than ten years ago, a typical value for power density of proposed converters was around $0,304 \mathrm{~W} / \mathrm{cm}^{3}$ $\left(5 \mathrm{~W} / \mathrm{inch}^{3}\right)$. Nowadays its value for the same device is targeting values around $1,5 \mathrm{~W} / \mathrm{cm}^{3}\left(25 \mathrm{~W} / \mathrm{inch}^{3}\right)$ [11]-[15]. There are several ways, how to meet upcoming requirements investigation of gain characteristic of power converter. In this part, the influence of proper material selection, as well as geometry of transformer core will be described.

Optimization of transformer design for high efficiency and high-power density converter is subjected to the reduction of overall transformer losses. These losses are composed from losses in windings and losses in transformer core (hysteresis losses, eddy currents). As will be later shown, both components of transformer losses are affected by maximal value of magnetic induction, so the proper choice of this parameter is crucial.

For copper losses, next formula can be derived:

$$
\begin{gathered}
P_{C u}=I_{\text {tot }}^{2} \times R_{C u}=\frac{I_{\text {tot }}^{2} \times n_{1}^{2} \times(M L T) \times \rho}{S_{O} \times K_{U}}, \\
I_{\text {tot }}=\sum_{j=1}^{k} \frac{n_{j}}{n_{1}} \times I_{j},
\end{gathered}
$$

where $I^{2}$ tot - averaged RMS value of winding currents [A], $R_{C u}$ - resistance of conductor in winding [ $\left.\Omega\right], \rho$-Wire effective resistivity $[\Omega \mathrm{m}], l_{j}-$ length of the conductor $[\mathrm{cm}]$, $n_{1}$ - number of turns - primary winding, (MLT) - Mean Length per Turn $[\mathrm{cm}], \mathrm{S}_{\mathrm{O}}-$ surface utilization factor $\left[\mathrm{cm}^{2}\right]$.

$$
\Delta B=10^{4} \frac{\int_{t 1}^{t 2} u_{1}(t) d t}{2 \times n_{1} \times S_{j}}=10^{4} \frac{U_{1}}{2 \times n_{1} \times S_{j}},
$$

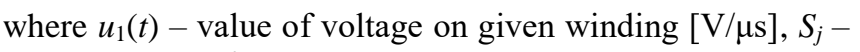
area of core $\left[\mathrm{cm}^{2}\right]$.

From (3) the number of turns for requested value of magnetic induction has this formulation

$$
n_{1}=10^{4} \frac{U_{1}}{2 \times \Delta B \times S_{j}} .
$$

Substituting (4) and (2) into (1) yields to required 
dependency of losses in transformer windings on induction ripple $\Delta \mathrm{B}$

$$
P_{C u}=\left(\frac{\rho \times \lambda_{1}^{2} \times I_{\text {tot }}^{2}}{4 \times K_{u}}\right) \times\left(\frac{(M L T)}{w_{A} \times A_{C}^{2}}\right) \times\left(\frac{1}{\Delta B}\right)^{2},
$$

where $\lambda_{1}=U_{\text {in_max }} \cdot T_{s w} \cdot D$.

From above mentioned equations is clear, that within increase of ripple content in magnetic induction, the losses in transformer windings will decrease rapidly.

For second part of overall losses - losses in transformer core, the situation is opposite. When maximal value of magnetic induction increases, the value of core losses also increases (6)

$$
P_{f e}=K_{f e} \times(\Delta B)^{\beta} \times A_{C} \times l_{m}
$$

where $l_{m}$-Magnetic path length $[\mathrm{cm}], \beta$ - Core loss exponent (for ferrite 2,6-2,7), $K_{f e}$ - parameter representing specific volume losses of material depending on saturation and switching frequency $\left[\mathrm{W} / \mathrm{cm}^{3}\right]$.

Losses in transformer's core, in addition to value of saturation, depend on core geometry, which is defined by factor of area, length, and by material properties of magnetics (parameter $K_{f e}$ ). It was mentioned that the ideal design of transformer depends on optimal value of parameter $\Delta \mathrm{B}$, thus next formula must be valid: $P_{t o t}=P_{C u}+$ $P_{f e}=$ minimum.

Graphical interpretation of this requirement is on Fig. 3. In order to minimize total transformer losses, next formulation must be valid

$$
\frac{d P_{t o t}}{d(\Delta B)}=\frac{d P_{f e}}{d(\Delta B)}+\frac{d P_{C u}}{d(\Delta B)}
$$

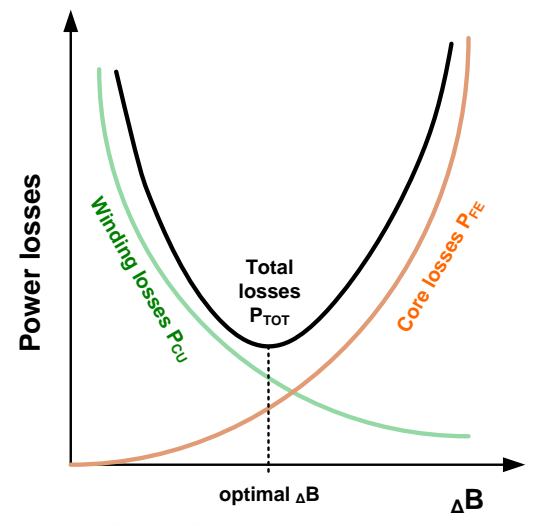

Fig. 3. Dependency of transformer losses on the ripple of magnetic induction.

Because of non-uniform shape of $P_{c u}$ and $P_{f e}$ characteristics (Fig. 3), it is not always true that optimal value of $\Delta \mathrm{B}$ shall fulfill this condition: $P_{f e}=P_{c u}$. Therefore, the optimal value of $\Delta \mathrm{B}$ must be found to meet

$$
\frac{d P_{f e}}{d(\Delta B)}=-\frac{d P_{C u}}{d(\Delta B)}
$$

As can be seen from (5) and (6) it is clear, that transformer losses are instead of $\Delta \mathrm{B}$ dependent on geometry and material properties of core. Targeting application requirements (high efficiency, high power density) transformer design must be focused almost on the proper selection of core properties.

When selecting core material, it is suitable to focus on the operating frequency of converter and consequently select material with the highest value of $\Delta \mathrm{B}$ for selected frequency (Fig. 4).

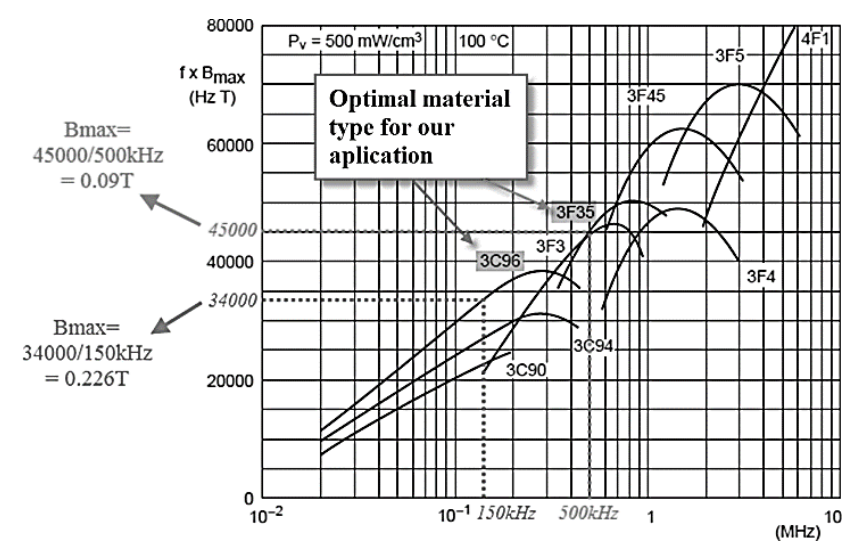

Fig. 4. Optimal selection curves for various operational conditions.

Then, from material volume loss characteristics, it is possible to determine (Fig. 5) expected core losses for selected operational point of transformer.

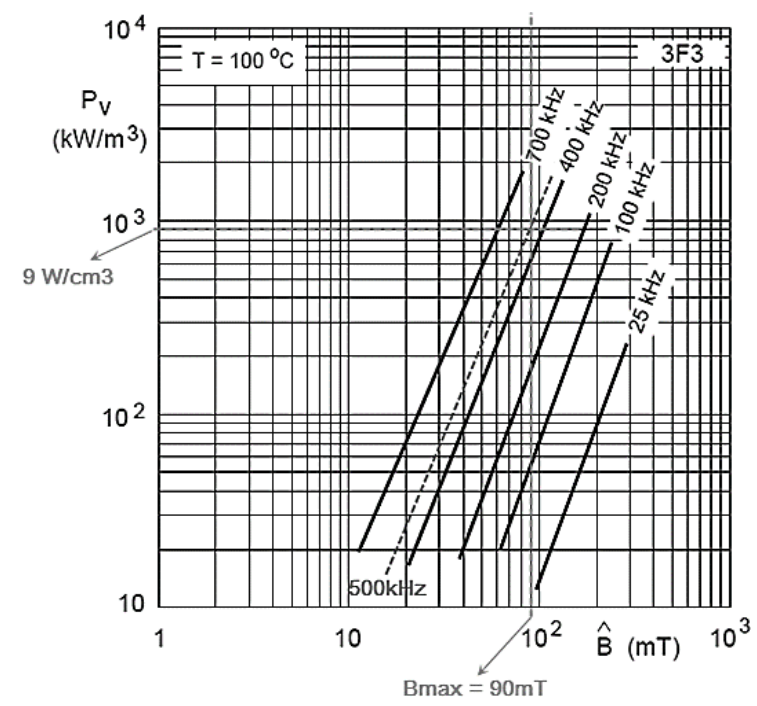

Fig. 5. Expected core losses for, selected operation point.

\section{TRANSFORMER CORE SELECTION FOR HIGH EFFICIENCY, HIGH POWER DENSITY OPERATION}

For the high efficiency and high-power density applications of power converter it is known, that PQ or RM shape of transformer core is preferred. This is due to compact shape and due to possibility for bobbin-less winding design.

Design of high-frequency transformer (Fig. 6) is complex task when contradictory requirements must be considered. It is the core volume of transformer and its total loses. With the use of previous analysis (1)-(8) it is possible to evaluate transformer losses in dependency on saturation induction as well as on core volume (Fig. 7). Through this process, it is possible to realize, what the amount of total transformer losses is. Thus, optimal selection (not exceeding allowed 
transformer losses and the value of saturation induction) of the transformer core (shape/volume) can be done.
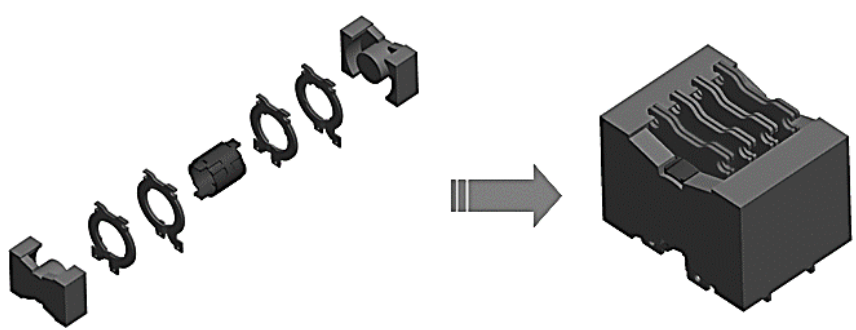

Fig. 6. Example of bobbin-less high-frequency transformer design.

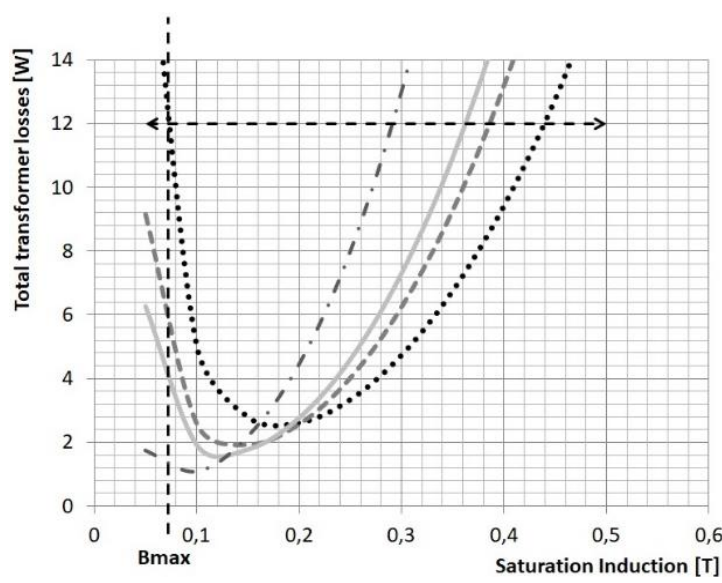

...PQ $32 / 30$ $--P Q 35 / 35$ PQ $40 / 40$ $-\cdot P Q 50 / 50$ $\leftrightarrow$ Ptot

Fig. 7. Total transformer losses in dependency of the value of saturation induction and core volume.

\section{RIPPLE CURRENT CANCELATION BY INTERLEAVED SWITCHING}

The output current $I_{\text {out }}$ of the LLC converter as is shown on the Fig. 8 is given by the sum of the current $i_{\text {out }}$ of rectifier diodes $\mathrm{D}_{1}$ and $\mathrm{D}_{2}$ and current of the filter capacitor $i_{\text {cout }}$. It notes that a value of the output capacitor ripple current can lead to their destruction. Usage of the output choke in order to reduce the ripple of the output current is not perspective solution in the case of high-density power supply, as a further choke is a bulky component, and introduces additional losses in the circuit.

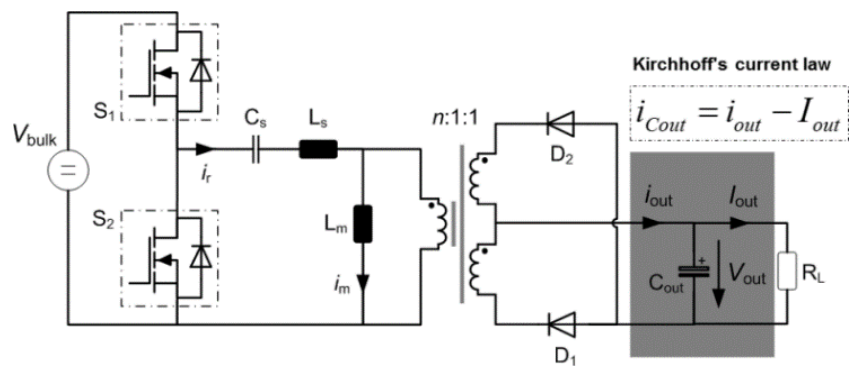

Fig. 8. Typical schematic of LLC converter.

By adapting 90 degrees' phase shift between switching of the LLC converter \#1 and LLC converter \#2, it is possible to achieve a significant decrease in the output capacitor's ripple current as is shown in Fig. 9 [16].

This solution eliminates the need for output choke and allows using output capacitors for significantly lower ripple current. Consequently, it is possible to optimize the number of output capacitors and thus increase the power density by reducing the volume of the converter.

To effectively reduce the ripple of the output current it is necessary for the two DC/DC converters to operate at the same switching frequency with the mutual phase shift of $90^{\circ}$. Setting the different switching frequency of LLC \#1 and LLC \#2 to evenly share the output load is not the optimal solution. In addition, the change of the duty cycle in the case of converters with pulse-width modulation (PWM) control is a simple solution, but in the case of resonant converters this is not suitable.

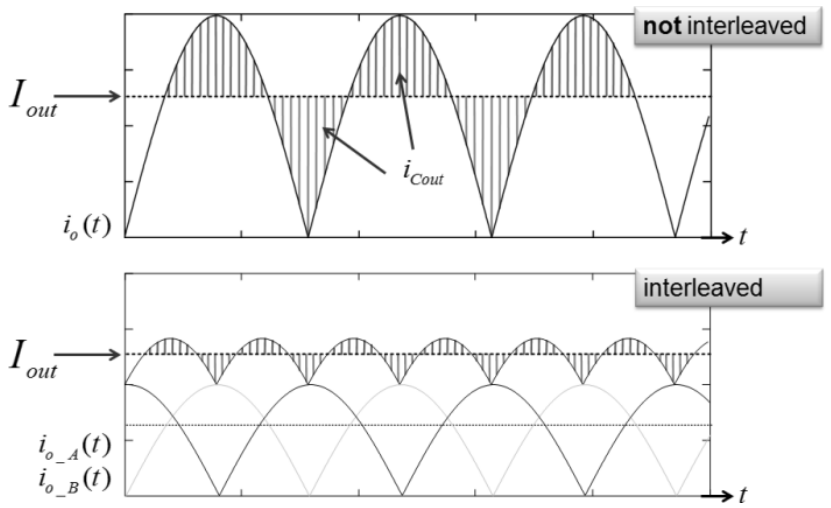

Fig. 9. Influence of interleaving for reduction of output capacitor's ripple current.

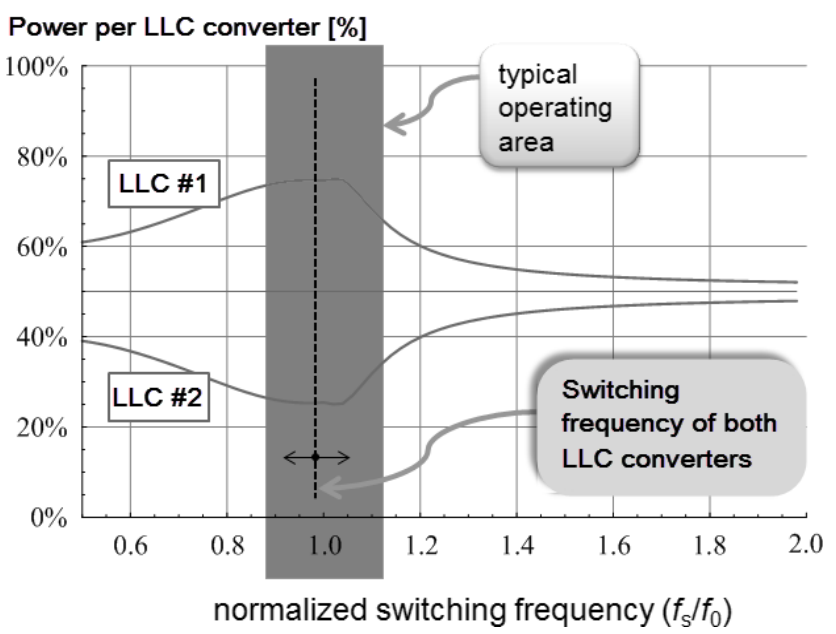

Fig. 10. Unbalanced distribution of output of power between the LLC converter due to tolerances of the resonant components.

The most suitable solution for ensuring the balanced output load sharing and reducing output ripple current of the parallel connected LLC converters can be achieved by split of input voltages of individual LLC converters (Fig. 11).

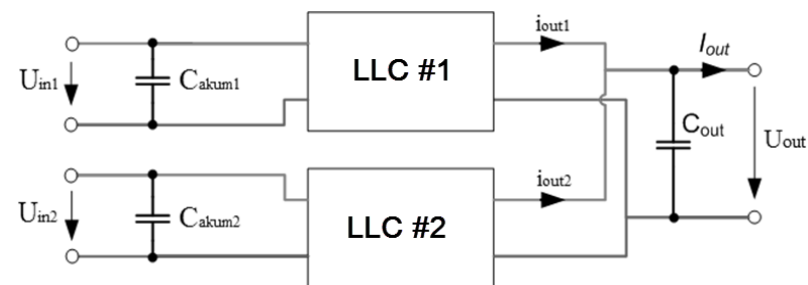

Fig. 11. Principe of the separated input voltage for parallel connected LLC converter.

Figure 11 shows principle of the separated input voltages for parallel connected LLC converters. To achieve balanced load sharing between both LLC converters the input voltages Uin1 and Uin2 shall be adjusted according to the actual tolerance of the resonant components of the particular LLC converter (Fig. 12). 


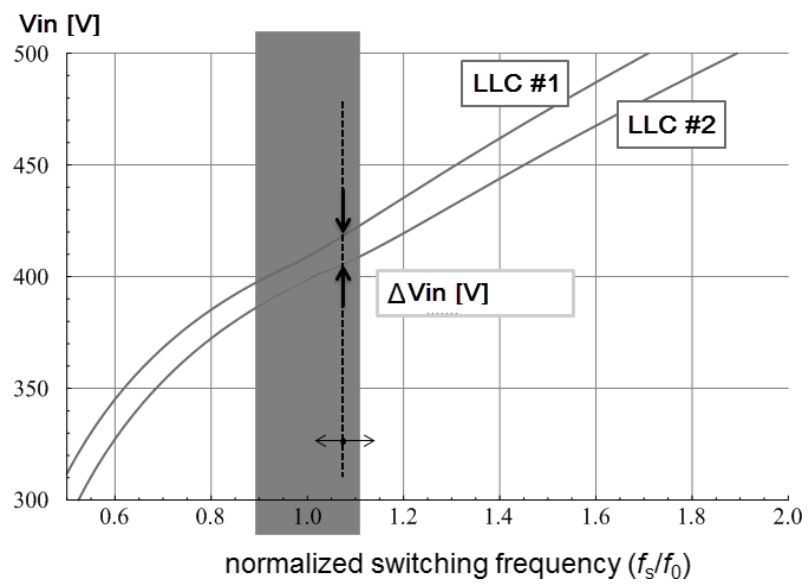

Fig. 12. Impact of the tolerance of resonant components on resonant frequency deviation.

\section{EXPERIMENTAL TESTING}

Using the two parallel cooperating LLC converters has a beneficial effect on the distribution of heat dissipation of the main transformers. Unlike full bridge topology with a single transformer of double power involvement of the two parallel cooperating LLC half bridge converters used two main transformers rated at half power output. This allows the use of a smaller transformer cores and the possibility of better spread distribution of heat losses occurring during operation of the converters.

The main advantage of the parallel cooperation of two LLC converters is possibility of increase of the efficiency by disconnecting one of the converters at low loads. To confirm this assumption, we performed measurements of the efficiency of each LLC converter individually and then measurement of the efficiency during their parallel operation [17], [18].

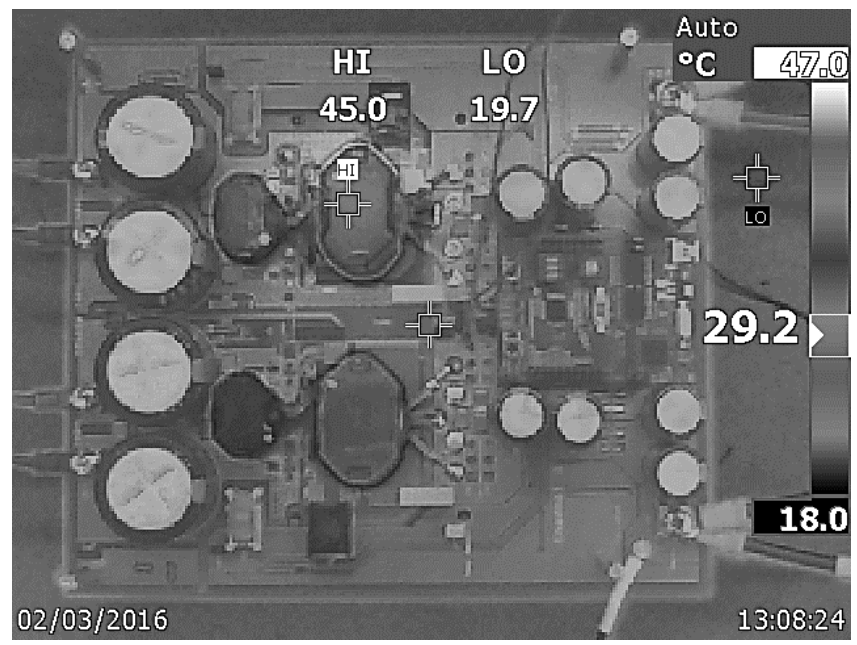

Fig. 13. Infrared scan of the prototype during operation.

Figure 14 shows the curves of efficiency of the LLC converter No. 1. During the measurement of efficiency, the LLC converter No. 2 was disconnected. LLC converter No. 1 was supplied by minimum $(340 \mathrm{~V})$, nominal $(380 \mathrm{~V})$, and finally by the maximum $(400 \mathrm{~V})$ input voltage. The output load was adjusted in the range from $5 \%$ to $50 \%$ $(1.2 \mathrm{~kW})$ of the nominal load. Figure 15 and Fig. 16 show desired performance in accordance with standard 80 PLUS Titanium [19], [20].

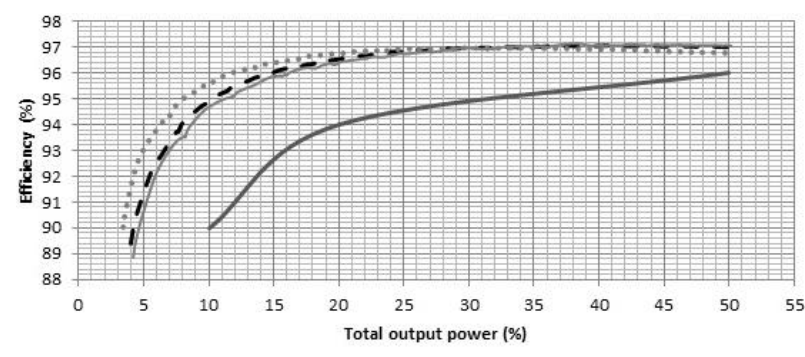

- - Vin_nom …v. Vin_min - Vin_max -80 pLus Titanium

Fig. 14. Efficiency of LLC \#1 at various input voltages.

Figure 14 displays the curves of efficiency of the two LLC converters with $50 \%$ output load sharing. During the measurement of efficiency both converters were supplied by minimum $(340 \mathrm{~V})$, nominal $(380 \mathrm{~V})$, and finally the maximum (400 V) input voltage.

Based on the measured efficiency of individual LLC converters and efficiency of parallel cooperation of both LLC converters with $50 \%$ output load sharing we made a comparison graph (Fig. 15). Consequently, we determined the thresholds levels for a single and parallel operation of LLC converters in order to operate with maximal efficiency in whole load range (Fig. 16).

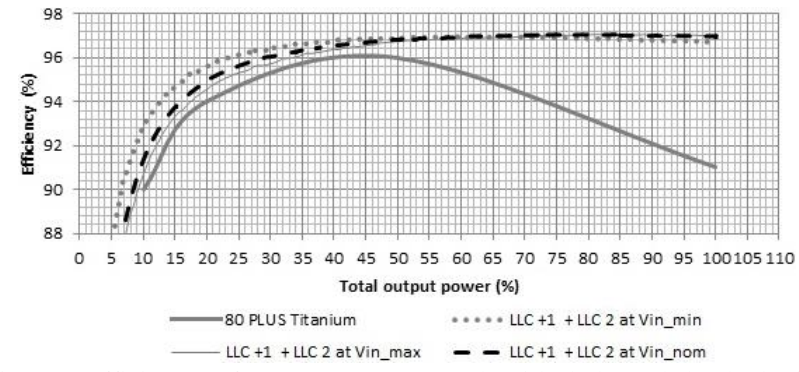

Fig. 15. Efficiency of prototype measured with balanced load sharing between LLC \#1 and LLC \#2 at various input voltages.
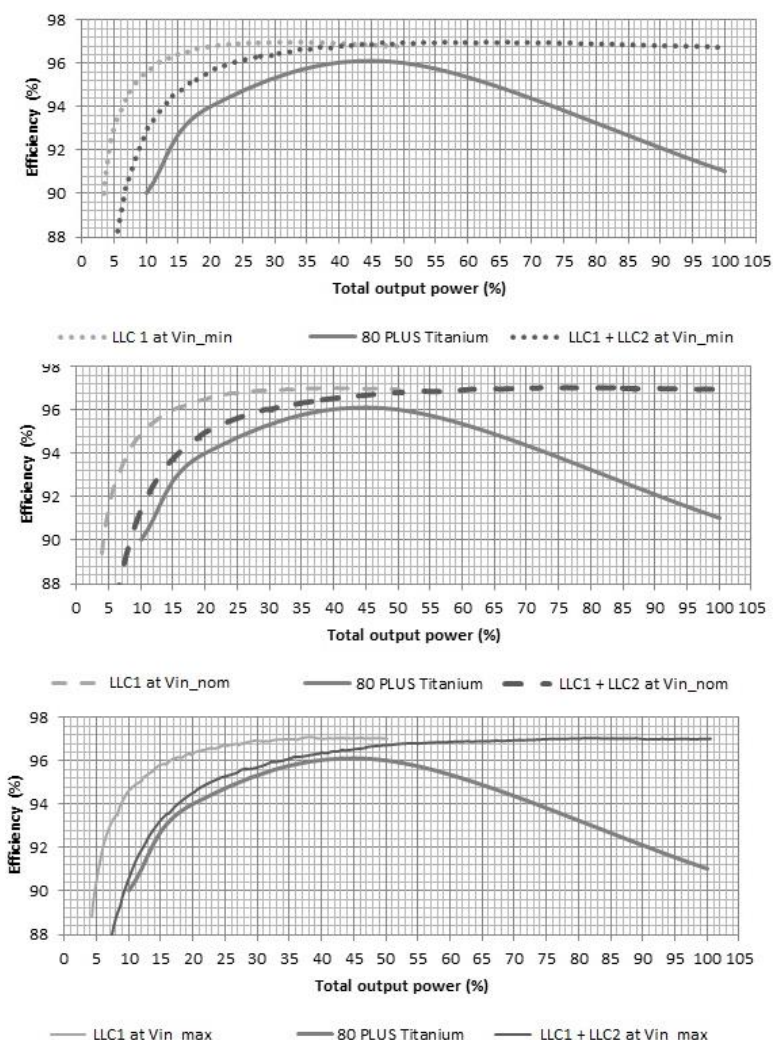

Fig. 16. Comparison of efficiency at various input voltage. 
As shown in Fig. 16 the efficiency of the prototype in the range of load to $45 \%$ of the nominal load is significantly higher, if the LLC converter \#2 is disconnected.

Based on the measured performance values for various input voltages we determined optimal threshold level of output load for employing the LLC \#2 converter to $48 \% \pm$ $2 \%$ in the case of increase of the load. In the case of decreasing of the output load the LLC \#2 converter will be stopped at $42 \% \pm 2 \%$ of nominal output load. Proposed thresholds levels provide sufficient hysteresis for stable operation under dynamic loads.

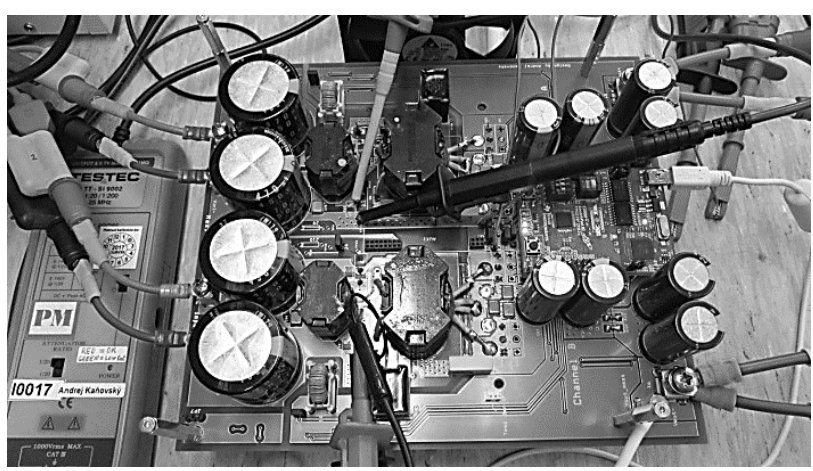

Fig. 17. Prototype of interleaved half-bridge LLC converter of nominal output voltage $48 \mathrm{~V}$ output power $2.4 \mathrm{~kW}$.

Thus, we can conclude that suitable turning off the LLC converter \#2 can achieve higher efficiency of the power supply at loads up to $45 \%$ of the nominal load compared to conventionally used solutions.

\section{CONCLUSIONS}

In this paper, interleaved, parallel-operated LLC converter was described. Proposed converter's design was focused on the achievement of improved qualitative indexes of power supplies for telecom-server applications.

Based on the proper transformer design and based on the investigation of component's tolerances, target operational parameters have been met. $500 \mathrm{kHz}, 1,5 \mathrm{~kW}$ LLC cells operated in parallel - interleaved mode extends almost constant high-efficiency operation from $45 \%$ of load up to the range of full - load of operation. Proposed converter gives higher variability for flexible operation targeting highpower density and high-efficiency characteristics compared to other solutions in the whole range of output power. Presented approach also provides much higher power density compared to single LLC solution. The reasons are related to the interleaved operation, while most of the passive components can be reduced due to ripple cancelation. The expectation is that through this approach it is possible to improve the power density twice. It must also be mentioned, that there are also other factors influencing the power density, i.e. selection of switching frequency, therefore it is hard to evaluate the exact improvement.

\section{REFERENCES}

[1] Z. Hu, Y. Qiu, L. Wang, Y.-F. Liu, "An interleaved LLC resonant converter operating at constant switching frequency", IEEE Trans. Power Electronics, vol. 29, no. 6, pp. 2931-2943, 2014. DOI:
10.1109/TPEL.2013.2273939.

[2] Shih-Ming Chen, Yong-Hong Haung, Yi-Yuan Chung, Yi-Hsun Hsieh, Tsorng-Juu Liang, "A novel interleaved LLC resonant converter", in 39th Annual Conf. IEEE Industrial Electronics Society (IECON 2013), Vienna, Austria, 2013, pp. 293-297. DOI: 10.1109/IECON.2013.6699151.

[3] V. Kindl, T. Kavalir, R. Pechanek, "Key construction aspects of low frequency wireless power transfer system using parallel resonance", in 17th European Conf. Power Electronics and Applications (EPE 2015 ECCE-Europe), Rajecke Teplice, Slovakia, 2015, pp. 1-5. DOI: 10.1109/ELEKTRO.2014.6848907.

[4] Li-Ming Wu, Ping-Shan Chen, "Interleaved three-level LLC resonant converter with fixed-frequency PWM control", in IEEE 36th Int. Telecommunications Energy Conf. (INTELEC 2014), Vancouver, BC, Canada, 2014, pp. 1-8. DOI: 10.1109/INTLEC.2014.6972209.

[5] P. Brandstetter, P. Chlebis, P. Simonik, "Active power filter with soft switching", International Review of Electrical Engineering, vol. 5, no. 6, pp. 2516-2526, 2010.

[6] W. Dai, "Modeling and efficiency-based control of interleaved LLC converters for PV DC microgrid", in IEEE Industry Applications Society Annual Meeting, 2015, pp. 1-8. DOI: 10.1109/IAS.2015.7356936.

[7] B. Dobrucky, T. Laskody, M. Prazenica, S. Kascak, "Analysis of VSI and $\mathrm{MxC}$ converters fed two-phase induction motor with the same magnitude of fundamental harmonic voltages", International Review of Electrical Engineering (IREE), vol. 9, no. 5, p. 898, 2014. DOI: 10.15866/iree.v9i5.3368.

[8] I. Kovacova, D. Kovac, "Inductive coupling of power converter's EMC”, Acta Polytechnica Hungarica, vol. 6, no. 2, pp. 41-53, 2009.

[9] B. Yang, "Topology investigation for front end $\mathrm{dc} / \mathrm{dc}$ power conversion for distributed power system", Virginia Polytechnic Institute and State University, 2003.

[10] Bo Yang, F. C. Lee, A. J. Zhang, Guisong Huang, "LLC resonant converter for front end DC/DC conversion", in APEC. Seventeenth Annual IEEE Applied Power Electronics Conf. and Exposition, vol. 2, pp. 1108-1112. DOI: 10.1109/APEC.2002.989382.

[11] D. K. Nayak, S. R. Reddy, "Comparison of the synchronous-rectified push-pull converter with LLC DC to DC converter", Arabian Journal for Science and Engineering, vol. 38, no. 4, pp. 913-926, 2013. DOI: 10.1007/s13369-012-0365-4.

[12] R. Bohm, C. Rehtanz, J. Franke, "Inverter-based hybrid compensation systems contributing to grid stabilization in medium voltage distribution networks with decentralized, renewable generation", Electrical Engineering, vol. 98, no. 4, pp. 355-362, 2016. DOI: 10.1007/s00202-016-0425-y.

[13] I. Apeland, R. Myhre, "Phase-shifted resonant converter having reduced output ripple", $6970366 \mathrm{~B} 2,2005$.

[14] H. Figge, T. Grote, N. Froehleke, J. Boecker, P. Ide, "Paralleling of LLC resonant converters using frequency controlled current balancing", in IEEE Power Electronics Specialists Conf., 2008, pp. 1080-1085. DOI: 10.1109/PESC.2008.4592073.

[15] T. Jin, K. Smedley, "Multiphase LLC Series resonant converter for microprocessor voltage regulation", in Conf. Record IEEE Industry Applications Conf. Forty-First IAS Annual Meeting, Tampa, FL, USA, 2006, vol. 5, pp. 2136-2143. DOI: 10.1109/IAS.2006.256838.

[16] W. Gong, S. Hu, M. Shan, H. Xu, "Robust current control design of a three phase voltage source converter", Journal of Modern Power Systems and Clean Energy, vol. 2, no. 1, pp. 16-22, 2014. DOI: 10.1007/s40565-014-0051-5.

[17] X. Guo, H. Wang, Z. Lu, B. Wang, "New inverter topology for ground current suppression in transformerless photovoltaic system application", Journal of Modern Power Systems and Clean Energy, vol. 2, no. 2, pp. 191-194, 2014. DOI: 10.1007/s40565-014-0057-z.

[18] M. Wu, D. D.-C. Lu, "Active stabilization methods of electric power systems with constant power loads: a review", Journal of Modern Power Systems and Clean Energy, vol. 2, no. 3, pp. 233-243, 2014. DOI: 10.1007/s40565-014-0066-y.

[19] S. Iqbal, "Double LLC resonant tanks based DC-DC converter with integrated dual transformers for PV power systems", in IEEE Power and Energy Conf. Illinois (PECI 2016), Urbana, IL, USA, 2016, pp. 1-6. DOI: 10.1109/PECI.2016.7459217.

[20] R. Ren, B. Liu, E. A. Jones, F. Wang, Z. Zhang, D. Costinett, "Dualoutput, three-level GaN-based dc-dc converter for battery charger applications", in IEEE Applied Power Electronics Conf. and Exposition (APEC 2016), Long Beach, CA, USA, 2016, pp. 24412448. DOI: 10.1109/APEC.2016.7468208. 